\title{
CrystEngComm
}

Cite this: CrystEngComm, 2013, 15, 6289

Received 12th April 2013,

Accepted 5th June 2013

DOI: $10.1039 /$ c3ce41013g

www.rsc.org/crystengcomm

\section{Advantages of mechanochemical cocrystallisation in the solid-state chemistry of pigments: colour-tuned fluorescein cocrystals $\dagger$}

\author{
Dejan-Krešimir Bučar, ${ }^{*}$ Stefan Filip, Mihails Arhangelskis, Gareth O. Lloyd \\ and William Jones
}

\begin{abstract}
Mechanochemical cocrystallisation was utilised to prepare fluorescein cocrystals involving pyridyl-based cocrystal formers, which exhibit different crystal structures, thermal and optical properties than those obtained via solution-based crystallisation.
\end{abstract}

Pigments are solid colourants regarded as insoluble in water and in commonly used solvents. ${ }^{1}$ They are extensively used in the production of a broad range of materials (e.g. plastics, inks, paints, organic electronics, optical data storage media) for both aesthetic reasons and functionality, ${ }^{2}$ and are the subject of a multi-billion US dollar industry. ${ }^{1}$ The colour of a pigment mainly depends on the molecular structure of its constituent, but is also strongly affected by particle size, morphology and crystal structure. It is known that different polymorphs of a pigment can display different colours (e.g. phthalocyanines ${ }^{3}$ and quinacridone ${ }^{3,4}$ ), and that solid solutions composed of structurally similar molecules can exhibit colours that significantly differ from those of the components (e.g. mixtures of 1,4-diketopyrrolo[3,4-c]pyrrol derivatives $^{2}$ ). Pigment solid-state chemistry has been discussed in the context of crystal engineering, ${ }^{3-5}$ but to our knowledge, no studies of hydrogen-bond-based pigment cocrystals have been reported in the literature so far.

Crystal engineering ${ }^{6}$ of cocrystals $^{7}$ (i.e. multi-component solids) is heavily applied to improve solid-state properties of organic compounds. In terms of pharmaceutical research, cocrystallisation has proved itself as very useful in advancing relevant physicochemical properties (e.g. bioavailability, hygroscopicity). ${ }^{8,9} \mathrm{~A}$ cocrystal approach to pigment design and production could benefit the pigment industry in many ways and, specifically, cocrystallisation could be used as a means to rearrange pigment constituents in their crystal lattice, as well as to introduce other chromophores into the lattice to alter the colouristic properties of the prepared solid. In addition, photochemical and heat stability,

Department of Chemistry, University of Cambridge, Lensfield Road, Cambridge CB21EW, UK. E-mail: dkb29@cam.ac.uk

$\dagger$ Electronic supplementary information (ESI) available: Crystallographic data, synthetic procedures and details concerning thermal, spectroscopic and crystallographic analyses. CCDC 908178-908181, 908183 and 908184. For ESI and crystallographic data in CIF or other electronic format see DOI: 10.1039/c3ce41013g as well as pigment fastness and solubility might be sufficiently altered using cocrystallisation. The advantage of such an approach lies in the opportunity to produce pigments with new properties rapidly and without the need to utilise environmentally unfriendly, labour- and cost ineffective retrospective molecular modifications.

Bearing in mind the enormous potential of cocrystals, the current lack of pigment cocrystal studies in the literature is somewhat surprising, and might be attributed to the insolubility of pigments in a broad range of solvents. More specifically, considering that the majority of cocrystal studies performed in the last twenty years relied on the growth of single crystals from solution and single crystal X-ray diffraction, it is not hard to envision that pigments might have been ignored by the crystal engineering community because of the great challenge of growing pigment cocrystals that are sufficient for single-crystal X-ray crystallographic studies..$^{10-14}$

Recent advances in crystal structure solution based on powder diffraction data, ${ }^{15,16}$ as well as in solvent-free mechanochemical cocrystal synthesis, ${ }^{17}$ however, have now positioned the community to explore potential benefits of pigment cocrystals. Here we present the results of a specific cocrystal study involving fluorescein (fls), a colourant insoluble in commonly utilised solvents, such as water, chloroform and ether. ${ }^{18}$ The present study demonstrates that mechanochemical cocrystallisation ${ }^{17,19}$ can be utilised as a means to prepare colour-tuned solids from readily available chemicals in high yields, and in a rapid and environmentally friendly manner. Solution-based crystallisation has, in contrast, been shown to yield cocrystals similar in colour and in poor yields. It is also shown that mechanochemical crystallisation yielded fewer cocrystal solvates than solution-based techniques, thus suggesting that mechanochemically prepared solids are likely to exhibit better thermal stabilities.

Fls occurs in three forms in the crystalline solid state: as a red powder with a quinoid structure (flsQ), a yellow powder with a zwitterionic structure and a white powder with a lactoid structure (flsL) (Scheme 1). ${ }^{16}$ The presence of hydroxyl and carboxylic groups in flsQ, as well as two hydroxyl groups in flsQ, marks fls as suitable for cocrystallisation using nitrogen-containing heteroaromatic cocrystal formers. We therefore selected acridine (acr), phenan- 
<smiles>O=C(O)c1ccccc1-c1c2ccc(=O)cc-2oc2cc(O)ccc12</smiles><smiles>O=C1OC2(c3ccc(O)cc3Oc3cc(O)ccc32)c2ccccc21</smiles><smiles>c1ccc2nc3ccccc3cc2c1</smiles><smiles>c1ccc2c(c1)cnc1ccccc12</smiles><smiles>c1cnccn1</smiles>

Scheme 1 Molecular structures of flsQ, flsL, acr, phe and pyr.

thridine (phi) and pyrazine (pyr), (shown in Scheme 1) to investigate the possibility of tuning the colour of crystalline fls by cocrystallisation. Mechanochemical cocrystallisation, along with solution-based cocrystallisation by evaporation (for comparison), was selected as crystallisation methods. The mechanochemical experiments were performed using a bench-top mill equipped with $10 \mathrm{~mL}$ stainless-steel grinding jars and two $7 \mathrm{~mm}$ stainless steel grinding balls per jar. The experiments involved physical mixtures of flsQ and the cocrystal former in either a $1: 1$ or $1: 2$ ratio, depending on the number of hydrogen-bond acceptors in the cocrystal former (see ESI $\dagger$ ). The mixtures were ground at a 30 $\mathrm{Hz}$ rate for 30 minutes in the presence of only $50 \mu \mathrm{L}$ of a liquid (i.e. nitromethane) to facilitate cocrystal formation. ${ }^{17}$

Notably, all reaction mixtures underwent a quantitative reaction to yield solids of different colours. We show that the cocrystal based on acr (A) exhibits an ochre colour, whereas cocrystals involving phi (B) and pyr (C) are yellow and pale green, respectively (Fig. 1: for solid-state UV-vis spectra see ESI†). The solids were investigated via powder X-ray diffraction (PXRD) and thermal analysis.
The structures of cocrystals involving acr, phi and phe were determined by crystal structure solution by simulated annealing and Rietveld refinement, using powder X-ray data ${ }^{10,20,21}$ obtained from a laboratory instrument. ${ }^{15}$ The crystallographic studies revealed that fls occurs in all three solids in its lactoid form (flsL), rather than the quinoid form (flsQ). The tautomeric transformation of flsQ into flsL is attributed to the presence of a heterocyclic base in the crystallisation vessel ${ }^{22}$ and was rather unexpected. It was found that acr and phi form $1: 2$ cocrystals (i.e. cocrystals A and B, respectively), while pyr forms a $1: 1$ cocrystal, C.

Structural analyses revealed that $\mathbf{A}$ is based on discrete threecomponent supramolecular assemblies wherein acr interacts with flsL through $\mathrm{O}-\mathrm{H} \cdots \mathrm{N}$ hydrogen bonds $[d(\mathrm{O} \cdots \mathrm{N})=2.949 \AA \mathrm{A}]$ whereby the acr molecule and the xanthene moiety of flsL exhibit a dihedral angle of about $126^{\circ}$. The discrete assemblies interact with each other to form stacks via $\pi \cdots \pi$ interactions $[d(\pi \cdots \pi) \sim 3.1 \AA$, $\angle$ (acr,acr) $\sim 13^{\circ}$ ] (Fig. 2b). Cocrystal $\mathbf{C}$ was found to display a crystal structure similar to that of $\mathbf{B}$. In particular, flsL and phi form discrete three-component hydrogen-bonded assemblies $[d(\mathrm{O} \cdots \mathrm{N})=$ $2.721 \AA]$ wherein phi and the xanthene moiety of flsL close an angle of about $116.7^{\circ}$. The assemblies stack into $1 \mathrm{D}$ polymers held together by $\pi \cdots \pi$ interactions $\left[d(\pi \cdots \pi) \sim 3.16 \AA\right.$, $\angle$ (phi,phi) $\left.\sim 26^{\circ}\right]$ (Fig. 2c). Cocrystal $\mathbf{C}$ is based on rippled $1 \mathrm{D}$ polymers held together by $\mathrm{O}-\mathrm{H} \cdots \mathrm{N}$ hydrogen bonds $[d(\mathrm{O} \cdots \mathrm{N})=2.694$ and $2.755 \AA$ A]. The polymers self-assemble with each other via $\mathrm{O}$ $\mathrm{H} \cdots \mathrm{O}$ hydrogen bonds. $[d(\mathrm{O} \cdots \mathrm{O})=2.962 \AA]$.

Attempts to prepare fls cocrystals with the same sets of cocrystal formers were also made by solvent crystallisation via slow solvent evaporation, and resulted in cocrystal formation in all three cases. Notably, the cocrystal growth was time-consuming (i.e. several days to weeks) and only very small amounts of material could be prepared using reasonable amounts of solvent owing to the low solubility of fls in common organic solvents. Furthermore, the crystallisation trials also often resulted in the concomitant
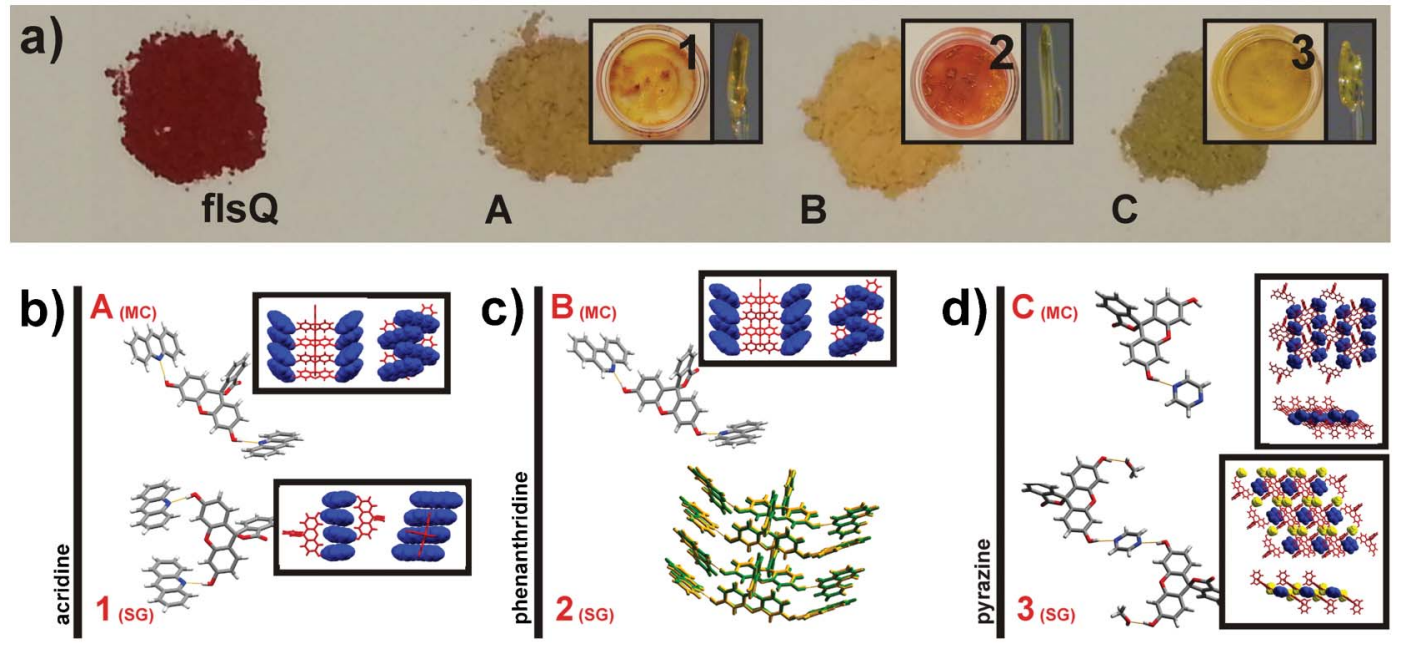

Fig. 1 a) Photographs of a bulk sample of flsQ, as compared to samples of the mechanochemically prepared cocrystal $\mathbf{A}, \mathbf{B}$ and $\mathbf{C}$. The insets depict the solutiongrown single crystals of $\mathbf{1}, \mathbf{2}$ and $\mathbf{3}$ (right), as well as the content of the crystallisation vials from which they were retrieved (left); b) crystal structures belonging to the mechanochemically (MC) prepared solids $\mathbf{A}, \mathbf{B}$, and $\mathbf{C}$, as compared to those of the corresponding solution-grown crystals (SG) $\mathbf{1}, \mathbf{2}$ and $\mathbf{3}$. 
precipitation of fls, which significantly diminished the purity of the prepared cocrystal bulk. Importantly, the colours of the solution-grown cocrystals differed from those obtained mechanochemically, and ranged from bright to dark yellow. The structures of the solution-grown cocrystals based on acr, phi and pyr were elucidated by single crystal X-ray diffraction. The crystallographic studies showed that acr and phi form 1: 2 cocrystals (i.e. $\mathbf{1}$ and 2, respectively), while pyr forms a 1:1:1 cocrystal $\mathrm{MeOH}$ solvate (3). All three cocrystals exhibit fls in its lactiod form, flsL.

Cocrystal 1 is based on U-shaped three-component assemblies held together by $\mathrm{O}-\mathrm{H}^{\cdots} \mathrm{N}$ hydrogen bonds $[d(\mathrm{O} \cdots \mathrm{N})=2.715$, $2.736 \AA]$. Within the assembly, the acr molecules are aligned in parallel at a centroid-to-centroid distance of $7.91 \AA$, and close angles of $73.9^{\circ}$ and $77.6^{\circ}$ with the xanthene moiety of flsL. The three-component assemblies interdigitate to form a six-component aggregate comprised of two flsL and four acr molecules that are held together by $\pi \cdots \pi$ and $\mathrm{C}-\mathrm{H} \cdots \mathrm{O}$ interactions $[d(\pi \cdots \pi)=$ $3.319 \AA, d(\mathrm{C} \cdots \mathrm{O})=3.364 \AA]$, in addition to the previously mentioned hydrogen bonds (Fig. 1b). Single crystals obtained from fls:phi solutions (2) were found to exhibit the same crystal structure as the mechanochemically prepared sample B (Fig. 1c). Lastly, flsL crystallises with pyr as a methanol solvate (3) in a $2: 1: 2$ fls:pyr:MeOH ratio. The crystal structure of 3 revealed that flsL assembles with pyr and a disordered $\mathrm{MeOH}$ molecule to form flat molecular tapes held together by $\mathrm{O}-\mathrm{H} \cdot \cdots \mathrm{N}$ and $\mathrm{O}-\mathrm{H} \cdots \mathrm{O}$ hydrogen bonds $[d(\mathrm{O} \cdots \mathrm{N})=2.791 \AA ; d(\mathrm{O} \cdots \mathrm{O})=2.649,2.684,2.800$, 2.914, $2.994 \AA$ ํ]. The molecular tapes assemble into a 3D structure sustained by $\mathrm{O}-\mathrm{H}^{\cdots} \mathrm{O}$ hydrogen bonds (Fig. 1d).

Whilst fluorescein is not a commercialised pigment, its solubility in commonly used solvents (e.g. water, chloroform, etc.) is very low and it can, therefore, be regarded as a model compound. The presented study should be, therefore, seen as a proof of principle that establishes that optical properties of (poorly soluble) colourants can be altered via mechanochemical cocrystallisation. The reported observations might also have broad implications on the development and production of dyes and pigments. Specifically, we believe that cocrystallisation could be used as a means to develop pigments and dyes with enhanced properties based on existing colourants and without the need of time-consuming, cost intensive and environmentally disadvantageous organic synthetic methods. Also, having in mind the utility of cocrystallisation to both improve or decrease the solubility of pharmaceutically active ingredients, ${ }^{9}$ it is reasonable to expect that poorly soluble colourants (i.e. pigments) could be rendered sufficiently soluble to be used as dyes, whereas highly soluble colourants (i.e. dyes) could be rendered insoluble to be used as pigments. Furthermore, it is proposed that the thermal stability of pigments, which is crucial to their performance, ${ }^{2}$ can also be altered through cocrystallisation, as already seen in the case of pharmaceutically relevant molecules. ${ }^{23}$

The presented study also highlights the efficiency of mechanochemistry in the screening for and preparation of cocrystals of colourants. In particular, we have shown that milling enables access to crystal forms that might be inaccessible through solution-based crystallisation without performing extensive highthroughput crystallisation screens. In addition, the mechano- chemically prepared cocrystals were not only obtained in quantitative yields and in very short reaction times (unlike the one obtained by solvent crystallisation), they also displayed a lower propensity towards undesired solvate formation. Altogether, the presented study suggests that mechanochemistry is a promising tool in the development of optimised dyes and pigments via cocrystallisation, an area of solid-state chemistry that is clearly overlooked and underdeveloped.

DKB acknowledges the Royal Society for a Newton International Fellowship and the Isaac Newton Trust (Trinity College, University of Cambridge) for funding. GOL thanks the Herchel Smith Fund for a research fellowship and funding. EPSRC is thanked for a studentship to MA.

\section{Notes and references}

1 W. Herbst and K. Hunger, Industrial Organic Pigments, WileyVCH Verlag GmbH \& Co. KGaA, Weinheim, 2004.

2 Z. Hao and A. Iqbal, Chem. Soc. Rev., 1997, 26, 203-213.

3 P. Erk, H. Hengelsberg, M. F. Haddow and R. van Gelder, CrystEngComm, 2004, 6, 474-483.

4 G. Lincke, Dyes Pigm., 2000, 44, 101-122.

5 E. F. Paulus, F. J. J. Leusen and M. U. Schmidt, CrystEngComm, 2007, 9, 131-143.

6 G. R. Desiraju, Angew. Chem., Int. Ed., 2007, 46, 8342-8356.

7 A. D. Bond, CrystEngComm, 2007, 9, 833-834.

8 N. Schultheiss and A. Newman, Cryst. Growth Des., 2009, 9, 2950-2967.

9 N. Shan and M. J. Zaworotko, Drug Discovery Today, 2008, 13, 440-446.

10 K. D. M. Harris, M. Tremayne and B. M. Kariuki, Angew. Chem., Int. Ed., 2001, 40, 1626-1651.

11 M. U. Schmidt, S. Bruhne, A. K. Wolf, A. Rech, J. Bruning, E. Alig, L. Fink, C. Buchsbaum, J. Glinnemann, J. van de Streek, F. Gozzo, M. Brunelli, F. Stowasser, T. Gorelik, E. Mugnaioli and U. Kolb, Acta Crystallogr., Sect. B: Struct. Sci., 2009, 65, 189-199.

12 M. U. Schmidt, R. E. Dinnebier and H. Kalkhof, J. Phys. Chem. $B, 2007$, 111, 9722-9732.

13 M. U. Schmidt, D. W. M. Hofmann, C. Buchsbaum and H. J. Metz, Angew. Chem., Int. Ed., 2006, 45, 1313-1317.

14 M. U. Schmidt, J. van de Streek and S. N. Ivashevskaya, Chem.Eur. J., 2009, 15, 338-341.

15 S. Karki, L. Fábián, T. Friščić and W. Jones, Org. Lett., 2007, 9, 3133-3136.

16 M. Tremayne, B. M. Kariuki and K. D. M. Harris, Angew. Chem., Int. Ed. Engl., 1997, 36, 770-772.

17 T. Friščić and W. Jones, Cryst. Growth Des., 2009, 9, 1621-1637.

18 The Merck Index, ed. M. J. O’Neil, Merck \& Co., Inc., Whitehouse Station, NJ, USA, 14th edn, 2006.

19 A. Delori, T. Friščić and W. Jones, CrystEngComm, 2012, 14, 2350-2362.

20 R. E. Dinnebier and S. J. L. Billinge, in Powder Diffraction: Theory and Practice, ed. R. E. Dinnebier and S. J. L. Billinge, Royal Society of Chemistry, Cambridge, UK, 2008, pp. 1-19.

21 K. D. M. Harris, in Advanced X-Ray Crystallography, ed. K. Rissanen, Springer, Berlin, Heidelberg, 2012, pp. 133-177.

22 N. A. Vodolazkaya, P. V. Shakhova and N. O. Mchedlov-Petrosyan, Russ. J. Gen. Chem., 2009, 79, 1437-1445.

23 C. B. Aakeröy, S. Forbes and J. Desper, J. Am. Chem. Soc., 2009, 131, 17048-17049. 